МАЛАШЕНКО С.M./ MALASHENKO S.M. ${ }^{1}$

канд. Техн. наук СМИЛОВЕНКО О.O./ dr SMILOVENKO O.O. ${ }^{2}$

ЕМЕЛЬЯНОВ В.К./ ЕМЕLYANOV V.K. ${ }^{1}$ канд. техн. наук ЧЕРНЕВИЧ O.B./ dr CHERNEVICH O.V. ${ }^{1}$

Przyjęty/Accepted/Принята: 05.02.2014;

Zrecenzowany/Reviewed/Рецензирована: 10.04 .2014 ;

Opublikowany/Published/Опубликована: 30.06.2014;

\title{
УСТРОЙСТВО ВРЕЗКИ В ПРОДУКТОПРОВОД ДЛЯ ПОДАЧИ ВОЗДУШНО-МЕХАНИЧЕСКОЙ ОГНЕТУШАЩЕЙ ПЕНЫ В ГОРЯЩИЙ РЕЗЕРВУАР ${ }^{3 *}$
}

\author{
A Device for Cutting Holes in the Pipelines in Order to Supply \\ a Burning Storage Tank with Air-Mechanical Firefighting Foam
}

\author{
Urządzenie do wcięcia się w rurociąg w celu podania \\ powietrzno-mechanicznej piany gaśniczej do płonącego zbiornika
}

\begin{abstract}
Аннотация
Цель: Совершенствование тактики подслойного тушения пожаров в резервуарах с нефтью и нефтепродуктами.

Введение: одним из приоритетных направлений по предупреждению масштабных утечек нефти и нефтепродуктов является противопожарная защита объектов хранения нефти и нефтепродуктов. Возникновение пожара в одном из резервуаров в резервуарном парке, несвоевременная его локализация и ликвидация могут привести к нарушению целостности резервуара, утечке нефти или нефтепродукта, быстрому распространению пожара по всему резервуарному парку, разрушению других резервуаров и еще более масштабному разливу нефти и нефтепродуктов. Подача пены низкой кратности подслойным способом возможна не только через пенопроводы системы пожаротушения, но и через технологические коммуникации (нефтепродуктопроводы, линии размывки донных отложений), расположенные в нижней части резервуара [1]. При этом практически полностью исключается возможность повреждения пеногенераторов и коммуникаций системы тушения взрывами и тепловыми потоками. Пена низкой кратности, поступающая из пеногенераторов, находящихся за обвалованием, выталкивает из трубопроводов горючее и поступает в резервуар [2].

Выводы: Разработано и изготовлено устройство для оперативной врезки (далее - УОВИ) для выполнения отверстий в технологических коммуникациях и последующей подачи огнетушащей воздушно-механической пены низкой кратности в слой горючего. УОВИ устанавливают на трубопроводы внешним диаметром 159, 168 или 219 мм с лакокрасочным покрытием. Проведена экспериментальная отработка тактико-технологических приемов оперативной врезки в технологические коммуникации резервуаров для реализации подслойного способа пожаротушения. С помощью УОВИ подают пену под слой горящего нефтепродукта в резервуаре, не оборудованном стационарно смонтированным пенопроводом для тушения. Применение УОВИ повысит эффективность пожаротушения, а также обеспечит более высокий уровень безопасности личного состава.

Значение для практики: тушение подслойным способом нефти и нефтепродуктов в резервуарах, не оборудованных стационарной системой пожаротушения, принципиально возможно через технологические коммуникации. Подача воздушно-

\footnotetext{
${ }^{1}$ У чреждение «Научно-исследовательский институт пожарной безопасности и проблем чрезвычайных ситуаций» Министерства по чрезвычайным ситуациям Республики Беларусь, г. Минск, ул. Солтыса, 183a; электронная почта: rifs.minsk@gmail.com / The Establishment «Research Institute of Fire Safety and Emergencies» of the Ministry for Emergency Situations of the Republic of Belarus, Minsk, Soltisa str, 183a; e-mail address: rifs.minsk@gmail.com;

${ }^{2}$ ГУО «Командно-инженерный институт» Министерства по чрезвычайным ситуациям Республики Беларусь, г. Минск, ул. Машиностроителей, 25; электронная почта: rifs.minsk@gmail.com / The State Educational Establishment «Command and Engineering Institute» of the Ministry for Emergency Situations of the Republic of Belarus, Minsk, Mashinostroiteley str, 25; e-mail address: rifs.minsk@gmail.com;

${ }^{3}$ Авторы внесли одинаковый вклад в статью / The authors contributed equally to this work.

* Artykuł został wyróżniony przez Komitet Redakcyjny / The article was recognised by the Editorial Committee/ Эту статью наградил Редакционный Совет
} 
механической пены осуществляется как в существующие патрубки, так и в отводы, полученные путем оперативной врезки. Задачи оперативной врезки решаются с помощью серийно выпускаемого оборудования.

Ключевые слова: пожар, воздушно-механическая огнетушащая пена, подслойный способ тушения нефти и нефтепродуктов, встроенный бандаж, задвижка

Вид статьи: с практики для практики

\begin{abstract}
Objective: Improvement of subsurface extinguishing technique of oil and oil products fires in storage tanks.

Introduction: One of priority directions in prevention of large-scale oil and oil products leaks is the fire protection of oil and oil products storage tanks. An emergence of a fire in one of the tanks in the storage tank facility, failure in its localizing and suppressing can lead to the damage to the tank, leakage of oil or oil products, fast spread of a fire through the entire storage tank complex, destruction of other tanks and even more large-scale leaks of oil and its products. The subsurface method of low expansion foam application is possible not only thanks to the foam pipelines of fire extinguishing systems, but also through the utility lines (oil pipelines, lines for washing out ground deposits), located in the lower part of a tank. Thus, the risk of a damage to the foam generators and pipelines of suppression system due to explosions and thermal streams is completely excluded. Low expansion foam arriving from foam generators located behind the protective dike pushes out the fuel from the pipelines and arrives into the tank.

Conclusions: An operative cutting integrated device (further-OCID) for cutting holes in utility lines and transferring fire extinguishing air-mechanical low expansion foam into the fuel layer has been designed and constructed. The OCID can be installed on the pipelines of 159,168 or $219 \mathrm{~mm}$ of external diameter and with lacquer coating. The tactical and technological methods of the operative cutting integrated device for utility lines of storage tanks, designed for the implementation of subsurface method of fire extinguishing have been experimentally developed. Implementation of OCID allows to transfer the foam under the layer of burning oil product in the storage tank not equipped with stationary mounted foam pipeline for extinguishing purposes. Application of the OCID will increase the efficiency of fire extinguishing and will provide higher level of staff's safety.

Implications for practice: Fire extinguishing of oil and oil products in storage tanks not equipped with stationary fire-extinguishing system with the help of subsurface method is principally possible through the utility lines. Supply of air and mechanical foam is carried out both through the existing branch pipes and in the branches which are received by the way of the operative cutting integrated device. The tasks of the operative cutting integrated device are solved with the help of serially produced equipment.
\end{abstract}

Keywords: a fire, air-mechanical foam fire extinguishing, subsurface method extinguishing oil and petroleum products, built-in bandage, pipeline valve

Type of article: best practice in action

\title{
Abstrakt
}

Cel: Udoskonalenie taktyki gaszenia metodą podpowierzchniową pożarów w zbiornikach z ropą i substancjami ropopochodnymi. Wprowadzenie: Jednym z priorytetowych kierunków w zapobieganiu wielkoskalowym wyciekom ropy i produktów ropopochodnych jest ochrona przeciwpożarowa obiektów do przechowywania ropy i jej pochodnych. Wybuch pożaru w jednym ze zbiorników w całym jego kompleksie, niewłaściwe zlokalizowanie i gaszenie pożaru mogą doprowadzić do uszkodzenia zbiornika, wycieku ropy lub ropopochodnych, szybkiego rozprzestrzenienia się pożaru na cały kompleks zbiorników, uszkodzenia innych zbiorników i jeszcze większego wycieku ropy i produktów ropopochodnych. Podanie piany o niskiej liczbie spienienia (piany ciężkiej) metodą podpowierzchniową jest możliwe nie tylko poprzez przewody systemu gaśniczego, lecz także poprzez rury technologiczne (rurociągi naftowe, przewody do oczyszczania z osadów dennych) zlokalizowane w dolnej części zbiornika. Przy tym praktycznie całkowicie wyklucza się możliwość uszkodzenia generatorów piany i rur technologicznych wskutek wybuchów i strumieni ciepła. Piana o niskiej liczbie spienienia wychodząca z generatorów piany umieszczonych za barierą ochronną wypycha z rurociagów paliwo i trafia do zbiornika.

Wnioski: Opracowano i skonstruowano urządzenie do operacyjnego wcięcia się w celu wywiercenia otworów w rurach technologicznych i następnie podania powietrzno-mechanicznej piany gaśniczej o niskiej liczbie spienienia do warstwy paliwa. Urządzenie ustawiane jest na rurociągach o zewnętrznej przekątnej 159, 168 lub $219 \mathrm{~mm}$ z pokryciem lakierniczym. Przeprowadzono badania eksperymentalne zastosowania urządzenia do wcięcia się w rury technologiczne zbiorników w celu realizacji gaszenia metodą podpowierzchniową. $\mathrm{Z}$ pomocą urządzenia podawana jest piana pod powierzchnię płonącego produktu naftowego w zbiorniku niewyposażonym w zamontowany na stałe przewód do podawania piany gaśniczej. Zastosowanie urządzenia zwiększy efektywność gaśniczą oraz zapewni większy poziom bezpieczeństwa załogi.

Znaczenie dla praktyki: Gaszenie metodą podpowierzchniową ropy i produktów naftowych w zbiornikach niewyposażonych w stacjonarne systemy gaśnicze jest zasadniczo możliwe dzięki rurom technologicznym. Podawanie powietrzno-mechanicznej piany jest realizowane poprzez dostępne kolanka, jak również przez odgałęzienia otrzymane dzięki wcięciu. Zadanie wycięcia otworu przeprowadzane jest za pomocą sprzętu produkowanego seryjnie.

Słowa kluczowe: pożar, powietrzno-mechaniczna piana gaśnicza, podpowierzchniowa metoda gaszenia ropy i produktów ropopochodnych, zawór, wbudowany bandaż

Typ artykułu: z praktyki dla praktyki

\section{1. Введение}

Пожары на объектах переработки и хранения нефти и нефтепродуктов достаточно редки, но, как правило, носят затяжной характер и наносят большой урон [3].
Основным средством тушения пожаров на этих объектах является пена средней и низкой кратности [3].

Огнетушащее действие воздушно-механической пены заключается в изоляции поверхности горючего от 
факела пламени, снижении вследствие этого скорости испарения жидкости и сокращении количества горючих паров, поступающих в зону горения, а также в охлаждении горящей жидкости. Роль каждого из этих факторов в процессе тушения изменяется в зависимости от свойств горящей жидкости, качества пены и способа ее подачи [3].

При подаче пены одновременно происходит разрушение пены от факела пламени и нагретой поверхности горючего. Накапливающийся слой пены экранирует часть поверхности горючего от лучистого теплового потока пламени, уменьшает количество паров, поступающих в зону горения, снижает интенсивность горения. Одновременно выделяющийся из пены раствор пенообразователя охлаждает горючее. Кроме того, в процессе тушения в объеме горючего происходит конвективный тепломассообмен, в результате которого температура жидкости выравнивается по всему объему, за исключением «карманов», в которых тепломассообмен происходит независимо от основной массы жидкости [3].

Одним из наиболее перспективных, надежных и безопасных является подслойный способ тушения нефти и нефтепродуктов в резервуарах, который применяется в ряде развитых зарубежных стран и активно внедряется в России [4].

При тушении пожаров в резервуарах подслойным способом применяется пена низкой кратности из фторсодержащих пленкообразующих пенообразователей целевого назначения.

Применение фторсодержащих пенообразователей является необходимым условием, поскольку пена на их основе инертна к воздействию углеводородов в процессе длительного подъема пены на поверхность нефтепродукта. Применение пены, получаемой на основе обычных пенообразователей для подачи в слой горючей жидкости, недопустимо, так как при прохождении через слой горючей жидкости она насыщается парами углеводородов и теряет огнетушащую способность [3].

Быстрой изоляции горящей поверхности пеной способствуют саморастекающаяся из пены водная пленка раствора пенообразователя, имеющая поверхностное натяжение ниже натяжения горючей жидкости, а также конвективные потоки, которые направлены от места выхода пены к стенкам резервуара. В результате конвективного тепломассообмена снижается температура жидкости в прогретом слое до среднеобъемной. Вместе с тем интенсивные восходящие потоки жидкости приводят к образованию на поверхности локальных участков горения, в которых скорость движения жидкости достигает максимальных значений. Эти участки, приподнятые над остальной поверхностью и называемые «бурунами», играют важную роль в процессе тушения. Чем выше «бурун», тем больше пены необходимо накопить для покрытия всей поверхности горящей жидкости. Для снижения высоты «буруна» пена подается через пенные насадки с минимальной скоростью [3].

Пена, всплывающая на поверхность через слой горючего, способна обтекать затонувшие конструкции и растекаться по всей поверхности горючего. Значительное снижение интенсивности горения достигается через 90-120 С с момента появления пены на поверх- ности. В это время наблюдаются отдельные очаги горения у разогретых металлических конструкций резервуара и в местах образования «бурунов». В дальнейшем, в течение 120-180 С происходит полное прекращение горения [3].

После загорания резервуара подача пены низкой кратности осуществляется непосредственно в слой нефтепродукта с использованием специальной системы подслойного тушения пожаров, находящейся в нижней части резервуара. Раствор пенообразователя подается с помощью передвижной пожарной техники или от системы автоматического пожаротушения [3].

При использовании передвижной пожарной техники для подслойного способа тушения резервуаров технологические трубопроводы резервуаров должны быть оснащены специальными патрубками для подключения высоконапорных пеногенераторов. Между пеногенератором и продуктопроводом дополнительно должна устанавливаться задвижка для предотвращения утечки нефтепродукта после прекращения подачи пены через высоконапорный пеногенератор, что делает способ трудоемким при отсутствии такого оборудования.

Оснащение резервуаров системой автоматического пожаротушения может быть осуществлена только в период проектирования или капитального ремонта.

\section{2. Устройство оперативной врезки}

Учреждением «Научно-исследовательский институт пожарной безопасности и проблем чрезвычайных ситуаций» МЧС Республики Беларусь в рамках задания ГНТП «Разработать и внедрить современные технику, средства и технологии для государственной системы предупреждения и ликвидации чрезвычайных ситуаций и гражданской обороны» [5] разработано УОВИ (патент на полезную модель № 8559 «Устройство оперативной врезки») [6] (рис. 1).

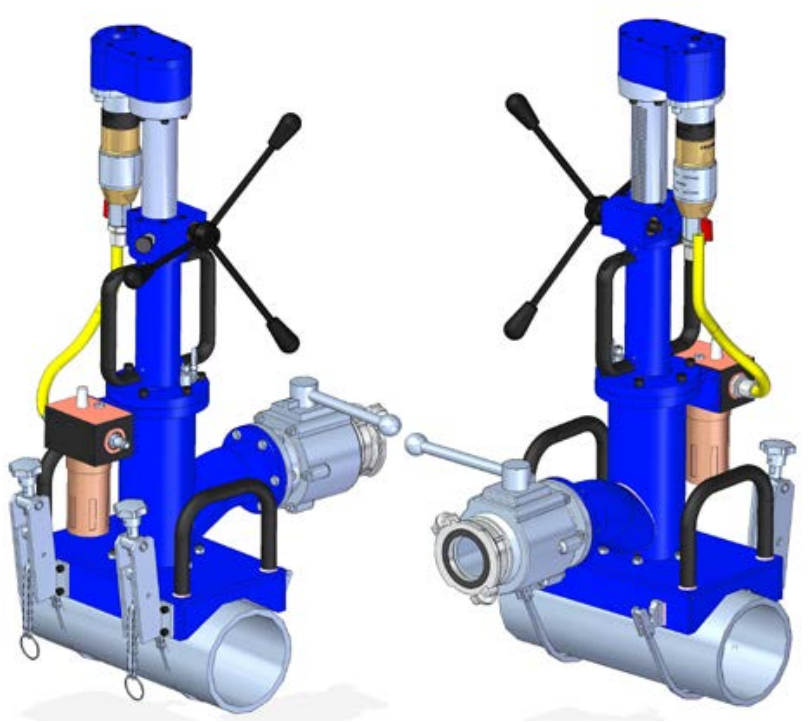

Рис. 1. Устройство оперативной врезки интегрированное Fig.1. The operative cutting integrated device

УОВИ предназначено для выполнения отверстий в технологических коммуникациях вертикальных стальных наземных резервуаров с нефтью и нефтепродуктами и последующей подачи огнетушащей воз- 
душно-механической пены низкой кратности в слой горючего.

Допускается использование УОВИ для выполнения работ, не связанных с пожаротушением (например, проведение оперативного ремонта трубопроводов).

УОВИ устанавливают на трубопроводы внешним диаметром 159, 168 или 219 мм с лакокрасочным покрытием. Конструкция УОВИ исключает утечку содержимого трубопровода. Привод УОВИ - пневматический двигатель с номинальным расходом сжатого воздуха $0,6-1,0$ м³/мин при давлении в пневматическом рукаве 0,6-0,8 МПа. Питание привода осуществляется от компрессоров или баллонов со сжатым воздухом, обеспечивающих запас воздуха на время не менее 5 мин работы. Диаметр выполняемого отверстия - 80 мм. Режущий инструмент - корончатая фреза с твердосплавными пластинами и высотой рабочей части 67 мм. Частота вращения фрезы - (80 \pm 10$)$ об/ мин. Подача/отвод фрезы - производится вручную. Возможность использования УОВИ на трубах разных диаметров обеспечивается сменными насадками.

\section{3. Натурные испытания УОВИ}

Натурные испытания УОВИ проведены на резервуаре вертикальном стальном РВС-1000, который находится на площадке ликвидации чрезвычайных ситуаций на складах нефти и нефтепродуктов полигона оперативно-тактической подготовки учреждения образования «Институт переподготовки и повышения квалификации МЧС Республики Беларусь». Схема установки приведена на рис. 2.

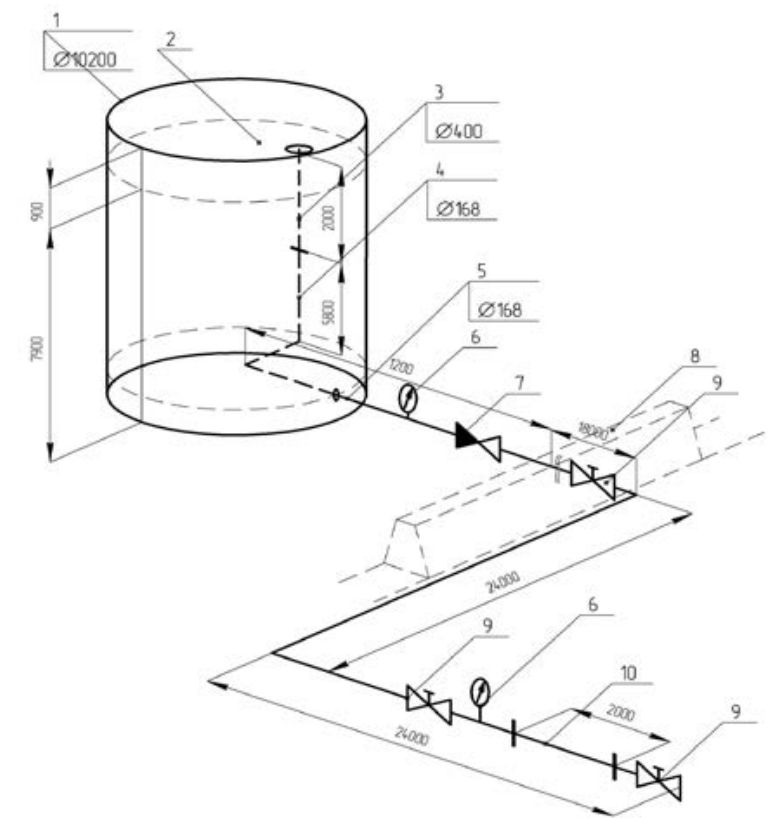

Рис. 2. Принципиальная схема установки

1 - РВС-1000; 2 - противень для горючей жидкости;

3, 4 - вертикальный трубопровод Ø400 и Ø168;

5 - экспериментальный трубопровод; 6 - манометр $(0-1,0)$ МПа; 7 - обратный клапан; 8 - обвалование резервуара; 9 вентиль запорный проходной; 10 - тренировочный участок

Fig. 2. Schematic diagram of the installation

1 - VST-1000; 2 - baking sheet for combustible liquid; 3, 4 vertical pipeline $\varnothing 400$ and $\varnothing 168 ; 5$ - experimental pipeline;

6 - manometer $(0-1,0) \mathrm{MPa} ; 7$ - check valve; 8 - earth deposit of the tank; 9 - straight through valve; 10 - training area
Резервуар представляет собой полый цилиндр, установленный на земляном основании с гравийной засыпкой толщиной $0,1-0,15$ м. Диаметр резервуара составляет 10,2 м, высота - 8,8 м. На высоте 7,9 м установлен противень для горючей жидкости с высотой борта 0,9 м. Днище противня усилено армирующими металлоконструкциями. В стенке резервуара выполнен вырез для входа во внутреннюю полость. Вокруг резервуара имеется обвалование. Минимальное расстояние до обвалования составляет 9,5 м. В стенке резервуара на уровне днища противня имеется сливной патрубок с двумя задвижками ЗКЛ-2 и трубопроводом диаметром 80 мм.

Для создания гидростатического давления резервуар оборудован вертикальным трубопроводом в виде стальной трубы Ø 400×10 мм высотой 2 м и трубы Ø 168×5 мм высотой 5,8 м. Участок экспериментального технологического трубопровода за обвалованием резервуара служит для отработки тактических приемов оперативной врезки. Длина тренировочного участка составляет 2 м.

На рис. 3 приведена принципиальная схема реализации способа подачи воздушно-механической огнетушащей пены в резервуар через действующий продуктопровод с помощью УОВИ.

Последовательность подготовки УОВИ к работе приведена в таблице 1, последовательность крепления УОВИ на трубе и сверление - в таблице 2.

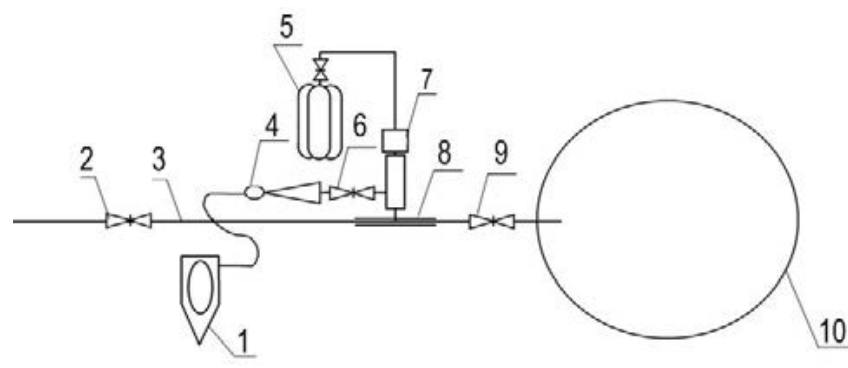

Рис. 3. Принципиальная схема реализации способа подачи воздушно-механической огнетушащей пены в резервуар через действующий продуктопровод

1 - пожарный аварийно-спасательный автомобиль; 2, 6, 9- шаровый кран (задвижка); 3 - действующий продуктопровод; 4 - высоконапорный генератор пены; 5 - источник сжатого воздуха; 7 - устройство врезки; 8 - бандаж; 10 - резервуар

Fig. 3. Schematic diagram of the submission method realization of air-mechanical foam fire-extinguishing into the tank through the acting product pipeline

1 - fire rescue vehicle; 2, 6, 9 - ball valve; 3 - acting product pipeline; 4 - high-pressure foam generator; 5 - source of compressed air; 7 - cut-in integrated device; 8 - bandage; 10 - tank 
Таблица 1. / Table 1.

Подготовка УОВИ к работе / Preparation of the OCID for work

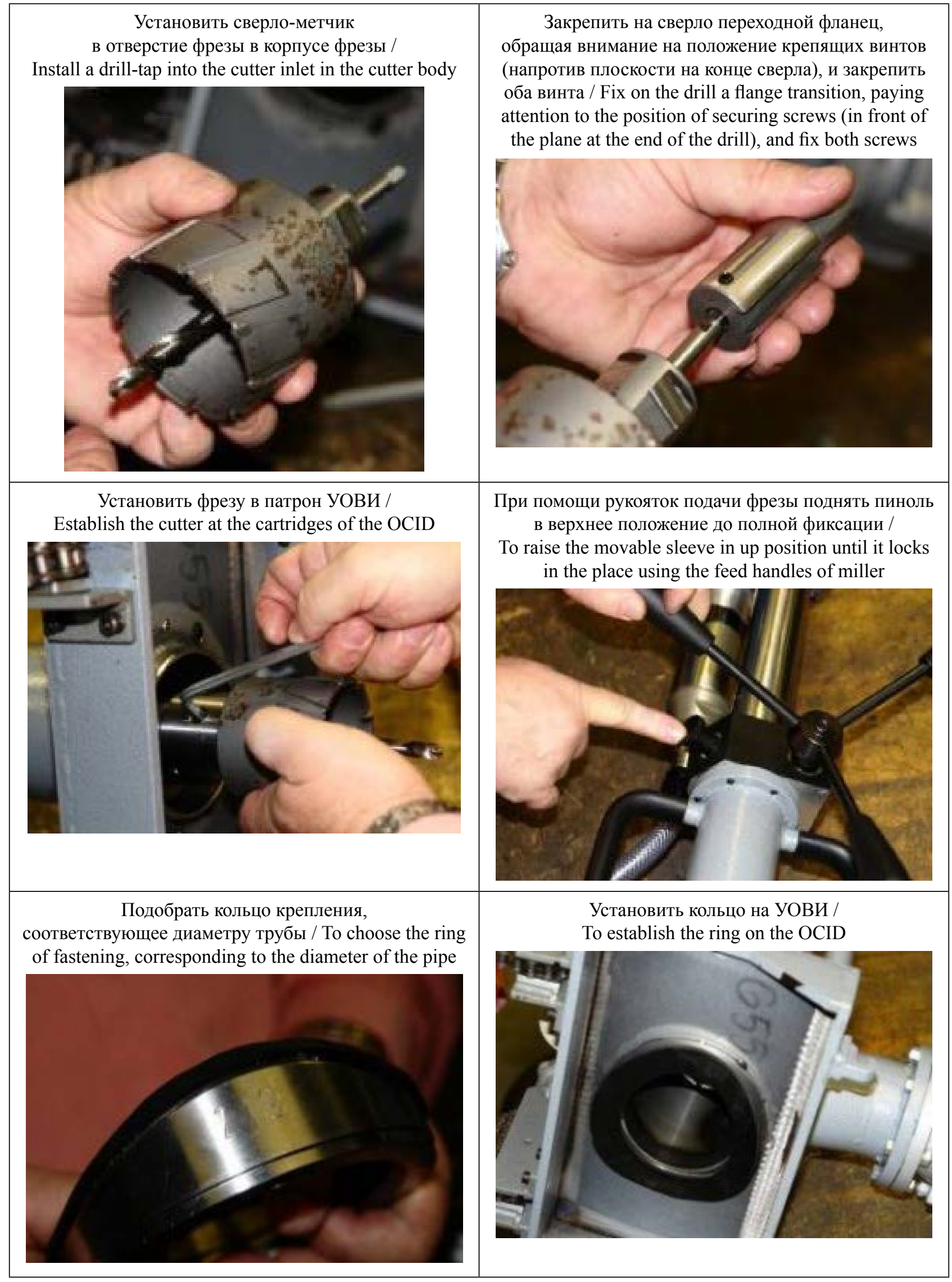


Таблица 2. / Table 2.

Крепление УОВИ на трубе и сверление / The OCID fastening on the pipe and drilling

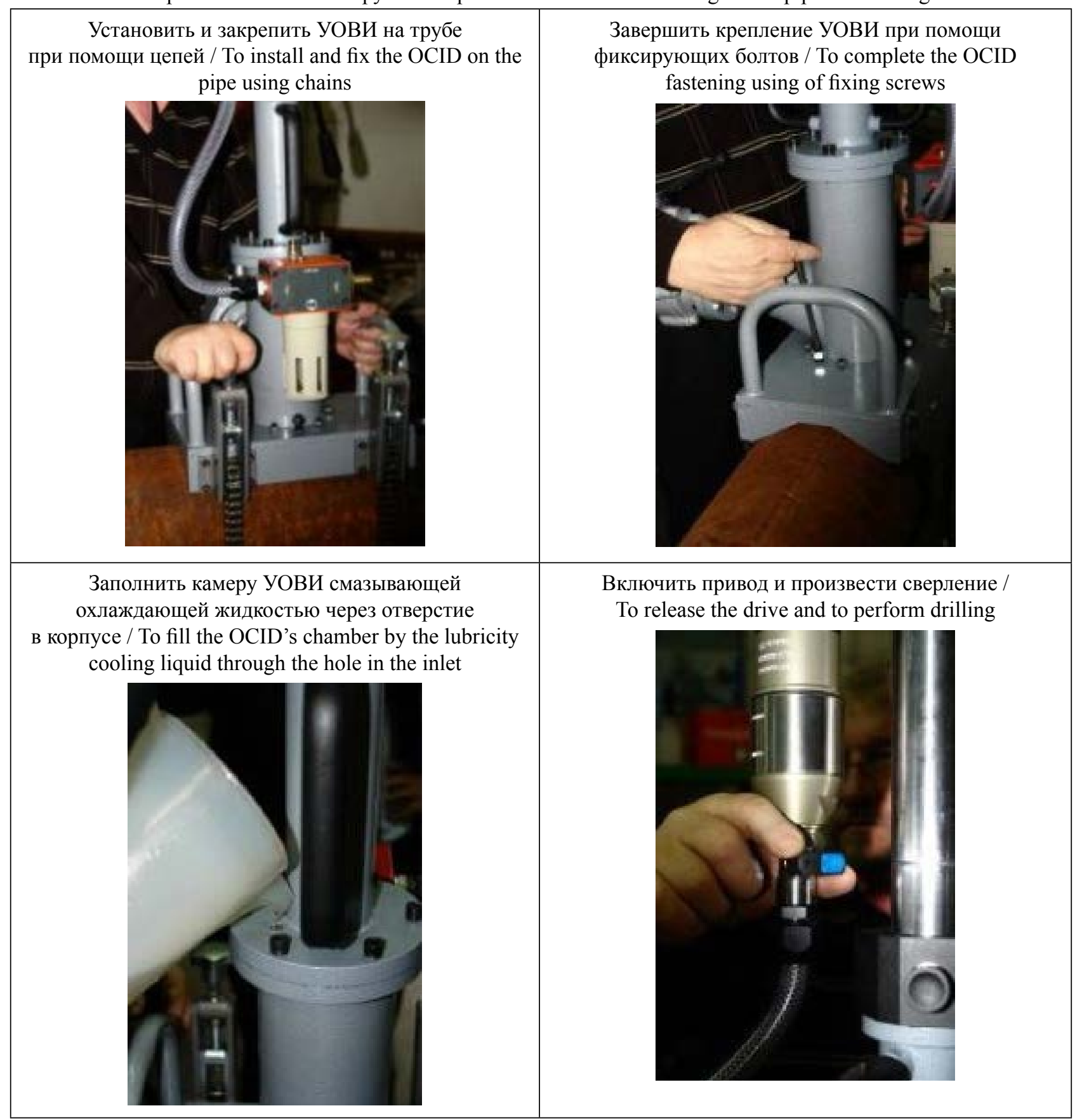

\section{4. Реализация подслойного способа пожаротушения}

Подача воздушно-механической огнетушащей пены в горящий резервуар и ликвидация чрезвычайной ситуации осуществляются следующим образом (рис. 4).

С помощью рукояток транспортировочно-монтажных (14) УОВИ устанавливают на трубопровод и фиксируют в вертикальном положении фиксаторами (12), затягивая цепи вручную путем поочередного вращения маховиков. Закрывают задвижку (10). Открывают заглушку клапана (8), через клапан во внутреннюю полость устройства подают смазывающую охлаждающую жидкость. Закручивают заглушку. К блоку подготовки воздуха (13) подают сжатый воздух от внешнего источника. Вращение шпинделя с режущим инстру- ментом осуществляется при получении пневматическим приводным механизмом (6) сжатого воздуха от внешнего источника через блок (13). При этом через редуктор (5) происходит передача вращающего момента от пневматического приводного механизма (6) к шпинделю с режущим инструментом, размещенным в корпусе 1. Нажатием на кнопку-фиксатор (7) разблокируют шестерни редуктора (4). Вращением рукоятки (3) по часовой стрелке осуществляют подачу режущего инструмента. На соединительную головку (11) устанавливают генератор пены. По завершении операции врезки отводят режущий инструмент вращением рукоятки (3) против часовой стрелки и фиксируют шестерни редуктора (4) кнопкой (7). На генераторе пены устанавливают рабочее давление и откры- 
вают задвижку (10). По окончании подачи огнетушащей пены задвижку (10) закрывают, генератор пены отключают, подачу сжатого воздуха прекращают [6].
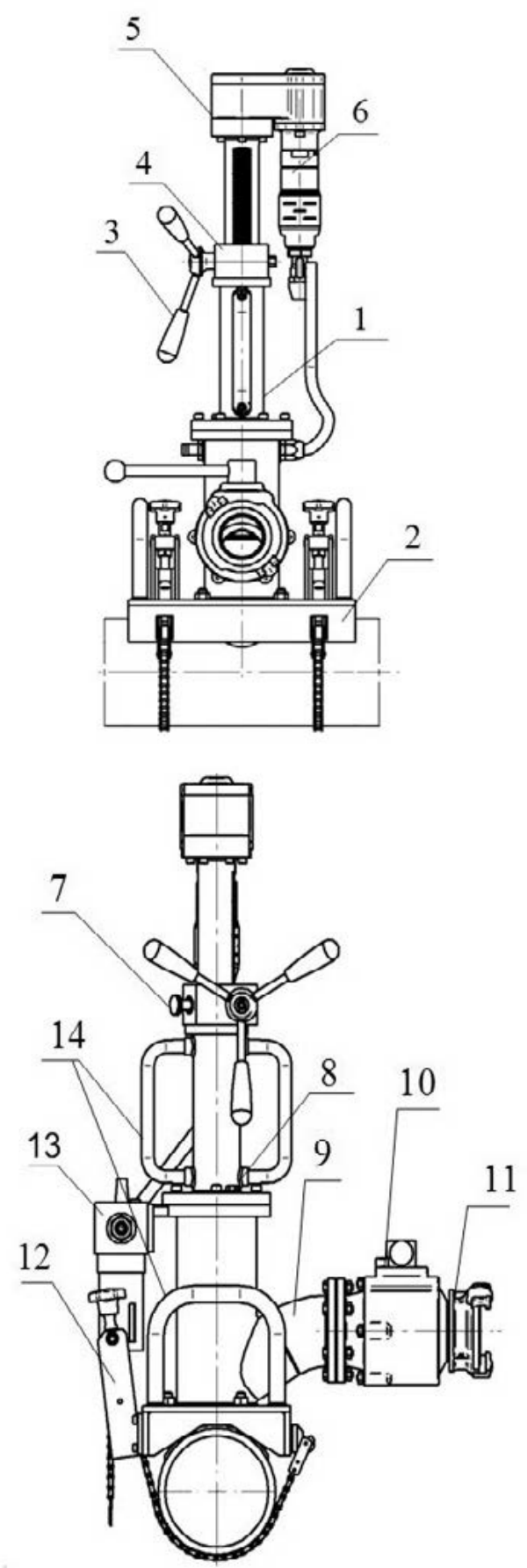

Рис. 4. Подача огнетушащей пены с помощью УОВИ 1 - корпус; 2 - встроенный бандаж; 3 - рукоятка подачи фрезы; 4 - редуктор подачи фрезы; 5 - редуктор вращения фрезы; 6 - пневматический приводной механизм;

7 - кнопка-фиксатор; 8 - клапан для подачи смазывающей охлаждающей жидкости; 9 - отвод; 10 - задвижка;

11 - головка соединительная; 12 - фиксатор;

13 - блок подготовки воздуха; 14 - рукоятки транспортировочно-монтажные

Fig. 4. Supplying of fire extinguishing foam by means of OCID 1 - case; 2 - built-in bandage; 3 - handle filing cutters; 4 - reducer filing cutters; 5 - reducer of cutter rotation; 6 - pneumatic actuator; 7 - button-lock; 8 - valve for supplying the lubricity cooling liquid; 9 - bend; 10 - valve; 11 - coupling head; 12 - latch; 13 - air preparation unit; 14 - transporting assembly handles

\section{5. Подведение итогов}

Технология подслойного тушения имеет ряд преимуществ:

- системы подслойного тушения менее подвержены повреждениям и разрушению в результате высокой температуры или взрывов, вызванных пожаром, а также в результате воздействия окружающей среды (ветер, дождь, снег);

- для тушения требуется меньшее количество пенообразователя, поскольку вся пена при подаче попадает в зону пожара и исключены ее потери из-за несовершенных методов распыления или восходящих воздушных потоков;

- системы подслойного тушения могут быть приведены в действие меньшим количеством персонала, так как их включение может быть произведено изза обвалования и для их применения не требуется использование передвижных пеноподъемников или других устройств;

- системы подслойного тушения гарантируют значительную безопасность персонала, поскольку тушение может производиться с минимальным количеством операций, требующих их выполнения в непосредственной близости от огня.

\section{6. Выводы}

Проведена экспериментальная отработка тактико-технологических приемов оперативной врезки в технологические коммуникации резервуаров для реализации подслойного способа пожаротушения.

С помощью УОВИ подают пену под слой горящего нефтепродукта в резервуаре, не оборудованном стационарно смонтированным пенопроводом для тушения. Применение УОВИ повысит эффективность пожаротушения, а также обеспечит более высокий уровень безопасности личного состава.

\section{Литература}

1. Instrukciia po tusheniiu pozharov nefti i nefteproduktov $\mathrm{v}$ rezervuarakh metodom podachi peny $\mathrm{v}$ sloi goriuchego, utverzhdennaia postanovlenem Ministerstva po chrezvychainym situaciiam Respubliki Belarus ot 26.06.2007 № 61.

2. Postanovlenie Ministerstva po chrezvychainym situaciiam Respubliki Belarus ot 11 ianvaria 2005 g. No 2 „Ob utverzhdenii Instrukcii o poriadke primeneniia penoobrazovatelei dlia tusheniia pozharov".

3. Rukovodstvo po tusheniiu nefti i nefteprodukotov v rezervuarakh i rezervuarnykh parkakh - M.:GUPO-VNIIPO, 1999.

4. Sharovarnikov A.F., Tushenie pozharov nefteproduktov v rezervuarakh podachei peny v sloi goriuchego Sharovarnikov, v: A.F. Sharovarnikov, V.P. Molchanov, „Transport i khranenie nefteproduktov" Sb statei - Vyp. 8-9 - M.:CNIITEneftekhim, 1996. - S. 5-10.

5. Chernevich O.V., Razrabotat taktiku tusheniia podsloinym sposobom nefti i nefteproduktov v rezervuarakh, ne oborudovannykh stacionarnoi sistemoi pozharotusheniia (Otchet o NIR NoGR200901141) [Tekst] / O.V. Chernevich, A.V. Makovchik, P.S. Mahahey, S.M. Malashenko etc.; NII PB i ChS MChS Belarusi. - Mn., 2010, s. 53, 33 ris., 9 tabl. Rus. - Dep. v GU „BelSA” 26.05.2010 g., No D201022.

6. Emelyanov V.K., Karach V.M., Chernevich O.V., Nawrocki O.D., Malashenko S.M., Patent na poleznuiu model No 8559 „Ustroistvo operativnoi vrezki integrirovannoe”, data nachala deistviia 23.11.2011. 
Малашенко Сергей Михайлович, магистр технических наук, главный специалист отдела научно-технической информации и маркетинга Учреждения «Научно-исследовательский институт пожарной безопасности и проблем чрезвычайных ситуаций» Министерства по чрезвычайным ситуациям Республики Беларусь.

Смиловенко Ольга Олеговна, кандидат технических наук, доцент кафедры пожарной аварийно-спасательной техники государственного учреждения образования «Командно-инженерный институт» Министерства по чрезвычайным ситуациям Республики Беларусь.
Емельянов Василий Константинович, главный специалист отдела исследований в области предупреждения чрезвычайных ситуаций Учреждения «Научно-исследовательский институт пожарной безопасности и проблем чрезвычайных ситуаций» Министерства по чрезвычайным ситуациям Республики Беларусь.

Черневич Ольга Владимировна, кандидат технических наук, ученый секретарь Учреждения «Научно-исследовательский институт пожарной безопасности и проблем чрезвычайных ситуаций» Министерства по чрезвычайным ситуациям Республики Беларусь. 